\title{
Prognostic Factors in Male Breast Cancer: A Single Centre Experience
}

\author{
Fevzi Coskun Sokmen \\ Department of Internal Medicine, HSU Dr. Abdurrahman Yurtaslan Oncology, Training and Research Hospital, Turkey
}

\begin{abstract}
Objective: To determine the prognostic factors by assessing the clinicopathological characteristics of the male patients with breast cancer (MBC).

Study Design: Observational study.

Place and Duration of Study: Department of Internal Medicine, HSU Dr. Abdurrahman Yurtaslan Oncology, Training and Research Hospital, Turkey, between January 2010 and November 2018.

Methodology: Data of patients with MBC were evaluated. Age $\geq 18$ years, diagnosis of breast carcinoma, and male gender were the inclusion criteria of the study. Patients were excluded from the study, if their data were incomplete. Ki-67, the status of estrogen receptor (ER), progesterone receptor (PR), and HER2 receptor were obtained from the hospital records. KaplanMeier method was performed for survival analysis. Cox regression analysis was used to determine independent prognostic factors of overall survivall (OS).

Results: Out of the 73 patients included in the study, 37 of them aged under 65, while 36 of them aged 65 or over. ER positivity was $94.5 \%$, while PR positivity was $87.7 \%$, and HER2 positivity was $13.7 \%$. It was found that as a result of the univariate analysis, the 5 -year OS of the elderly group ( $\geq 65$ years) was lower compared to the younger group ( $<65$ years, $74.2 \%$ vs. $93.3 \%, p=0.022)$. Age, tumor grade, and T stage were included in the multivariate Cox regression analysis and only advanced age was found to be an independent poor prognostic factor (HR: 3.068, 95\% Cl: 1.013-9.293, p=0.047).
\end{abstract}

Conclusion: Advanced age might be an independent poor prognostic factor for patients with MBC.

Key Words: Breast cancer, Elderly, Male, Prognosis.

How to cite this article: Sokmen FC. Prognostic Factors in Male Breast Cancer: A Single Centre Experience. J Coll Physicians Surg Pak 2020; 30(12):1285-1290.

\section{INTRODUCTION}

Breast cancer, which is one of the most prevalent malignancies among females, develops quite rarely in males. ${ }^{1-4}$ Male breast cancer (MBC) accounts for nearly $1 \%$ of the cancers, which occur among males. Nowadays, the incidence of $\mathrm{MBC}$, which was 1.0 per 100,000 about 50 years ago, has increased to $1.2 .^{5}$

Breast cancer occurs at an advanced age among males compared to females. ${ }^{1,6}$ MBC also differs from female breast cancer (FBC) in terms of pathological characteristics. ${ }^{7}$ Lymph node metastasis and positivity of the estrogen receptor(ER) are more prevalent in patients, who have MBC compared to those with $\mathrm{FBC}{ }^{5}$ BRCA2 mutation is more prevalent in males with breastcancer compared to females. ${ }^{7}$

Correspondence to: Dr. Fevzi Coskun Sokmen, Department of Internal Medicine, HSU Dr. Abdurrahman Yurtaslan Oncology, Training and Research Hospital, Turkey

E-mail: fcoskunsokmen@gmail.com

Received: October 06, 2020; Revised: November 20, 2020;

Accepted: December 08, 2020

DOI: https://doi.org/10.29271/jcpsp.2020.12.1285
Treatment in localised MBC involves surgical and adjuvant treatments analogous to $\mathrm{FBC}$. Due to its rarity, prospective randomised clinical trials, which include solely those with MBC, are very limited. ${ }^{1,8}$ Since it rarely occurs, a very small number of patients with MBC can be included in these trials, albeit male patients are among the inclusion criteria of most trials on breast cancer. ${ }^{1,9}$ It is considered that clinicopathological differences between genders, hormonal and biological characteristics, and genetic variations may impact treatment responses, though it has been suggested that MBC can be treated like FBC. ${ }^{1,10}$ Thus, further studies related to MBCareneeded.

Remarkable advances have occurred in the treatment of breast cancer in recent years. It was aimed through this study to determine the prognostic factors by assessing the clinicopathological characteristics of the patients with MBC, the treatments they received, and the treatment responses. Moreover, it was focused on the responses of patients with MBC, who had been treated over the last 10 years, to up-to-date novel treatments.

\section{METHODOLOGY}

A total of 92 male patients with breast carcinoma, who were admitted to Dr Abdurrahman Yurtaslan Oncology Training and Research Hospital, between January 2010 and November 2018 were evaluated. 
Table I: General clinical and demographic features of the patients.

\begin{tabular}{|c|c|c|c|c|c|}
\hline & & $\begin{array}{c}\text { All patients } \\
\text { n:73 (\%) }\end{array}$ & $\begin{array}{c}<65 \text { years } \\
n: 37(\%)\end{array}$ & $\begin{array}{c}\geq 65 \text { years } \\
\mathrm{n}: 36(\%)\end{array}$ & p-value \\
\hline \multicolumn{6}{|c|}{ ECOG PS } \\
\hline & 0 & $15(20.5)$ & $9(24.3)$ & $6(16.7)$ & 0.418 \\
\hline & $1-2$ & $58(79.5)$ & $28(75.7)$ & 36 (83.3) & \\
\hline \multicolumn{6}{|c|}{ Histopathology } \\
\hline & IDC & $65(89.0)$ & $34(91.9)$ & 31 (86.1) & 0.479 \\
\hline & Other & $8(11.0)$ & $3(8.1)$ & $5(13.9)$ & \\
\hline \multicolumn{6}{|c|}{ Grade } \\
\hline & $1-2$ & $34(46.6)$ & $19(51.4)$ & $15(41.7)$ & 0.407 \\
\hline & 3 & $39(53.4)$ & $18(48.6)$ & $21(58.3)$ & \\
\hline \multicolumn{6}{|c|}{ T stage } \\
\hline & $\mathrm{T} 1$ & $17(23.3)$ & $8(21.6)$ & $9(25.0)$ & 0.449 \\
\hline & $\mathrm{T} 2$ & $48(65.8)$ & $26(70.3)$ & $22(61.1)$ & \\
\hline & T3 & $5(6.8)$ & $1(2.7)$ & $4(11.1)$ & \\
\hline & T4 & $3(4.1)$ & $2(5.4)$ & $1(2.8)$ & \\
\hline \multicolumn{6}{|c|}{ N stage } \\
\hline & NO & $29(39.7)$ & $10(27.0)$ & $19(52.8)$ & 0.102 \\
\hline & N1 & $19(26.0)$ & $10(27.0)$ & $9(25.0)$ & \\
\hline & $\mathrm{N} 2$ & $16(21.9)$ & $11(29.7)$ & $5(13.9)$ & \\
\hline & N3 & $9(12.4)$ & $6(16.2)$ & $3(8.3)$ & \\
\hline \multicolumn{6}{|c|}{ ER } \\
\hline & Positive & $69(94.5)$ & $34(91.9)$ & $35(97.2)$ & 0.615 \\
\hline & Negative & $4(5.5)$ & $3(8.1)$ & $1(2.8)$ & \\
\hline \multicolumn{6}{|c|}{ PR } \\
\hline & Positive & $64(87.7)$ & $30(81.1)$ & $34(94.4)$ & 0.152 \\
\hline & Negative & $9(12.3)$ & 7 (18.9) & $2(5.6)$ & \\
\hline \multicolumn{6}{|c|}{ Her2 } \\
\hline & Positive & $10(13.7)$ & $6(16.2)$ & $4(11.1)$ & 0.736 \\
\hline & Negative & $63(86.3)$ & 31 (83.8) & $32(88.9)$ & \\
\hline \multicolumn{6}{|c|}{ Adjuvant CT } \\
\hline & No & $16(21.9)$ & $5(13.5)$ & $11(30.6)$ & 0.504 \\
\hline & $A C$ & $10(13.7)$ & $5(13.5)$ & $5(13.9)$ & \\
\hline & $\mathrm{AC}+$ Taxane & $19(26.0)$ & $11(29.7)$ & $8(22.2)$ & \\
\hline & AC + Taxane + Trastuzumab & $10(13.7)$ & $6(16.2)$ & $4(11.1)$ & \\
\hline & Other & $18(24.7)$ & $10(27.0)$ & $8(22.2)$ & \\
\hline \multicolumn{6}{|c|}{ Adjuvant Tamoxifen } \\
\hline & Yes & $66(90.4)$ & $31(83.8)$ & $35(97.2)$ & 0.107 \\
\hline & No & $7(9.6)$ & $6(16.2)$ & $1(2.8)$ & \\
\hline
\end{tabular}

IDC: Invasive ductal carcinoma; ER: estrogen receptor; PR: progesterone receptor receptor; CT: Chemotherapy, AC: Anthracycline cyclophosphamide.

Age $\geq 18$ years, diagnosis of breast carcinoma, and male gender were inclusion criteria of the study. Patients who had incomplete data and metastatic disease were excluded from the study. Five out of 92 MBC patients were excluded from the study because of incomplete data; and 14 ( 7 under 65 years old, 7 over 65 years old) due to metastatic disease. Data related to the age and comorbidity of the patients, Ki-67 level of the tumor, the status of estrogen receptor (ER), progesterone receptor (PR), and HER2 receptor; the neoadjuvant treatments practised to the tumor, surgical data, adjuvant and systemic treatment data, TNM stage of the disease and the last contact dates of the patients were obtained from the hospital records.

Table II: Results of univariate and multivariate analyses for OS.

\begin{tabular}{|c|c|c|c|c|c|c|}
\hline \multirow{3}{*}{\multicolumn{2}{|c|}{ All }} & \multicolumn{3}{|c|}{ Univariate } & \multicolumn{2}{|c|}{ Multivariate } \\
\hline & & 5-year OS (\%) & Median OS, months $(95 \% \mathrm{Cl})$ & p-value & HR $(95 \% \mathrm{Cl})$, OS & p-value \\
\hline & & 84.3 & $183(109.5-256.5)$ & - & - & - \\
\hline \multicolumn{7}{|c|}{ Age } \\
\hline & $<65$ year & 93.3 & NR & 0.022 & 1.00 & 0.047 \\
\hline & $\geq 65$ year & 74.2 & $119(75.2-162.8)$ & & 3.068 (1.013-9.293) & \\
\hline \multicolumn{7}{|c|}{ ECOG PS } \\
\hline & 0 & NA & NR & 0.217 & - & - \\
\hline
\end{tabular}




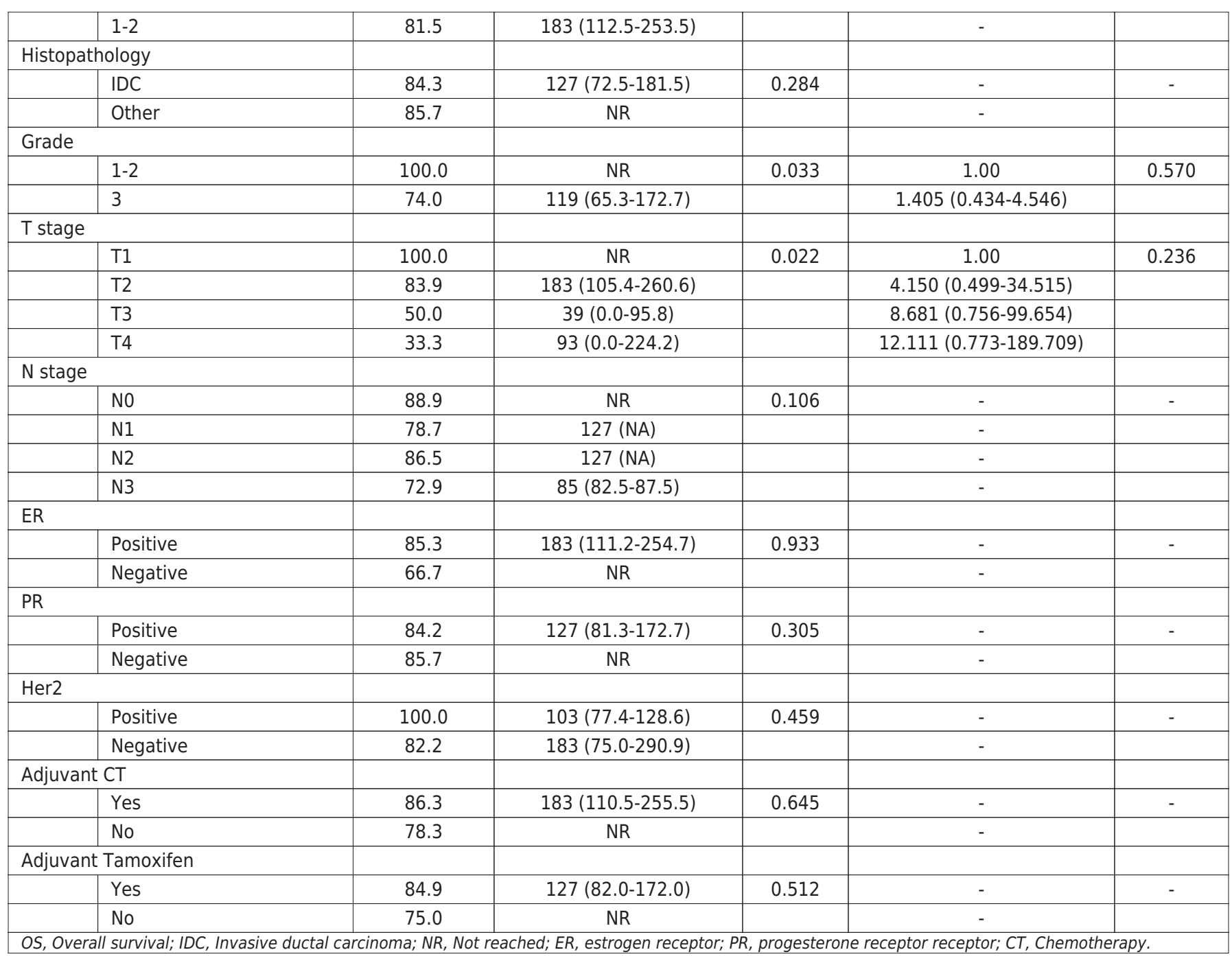

According to the definition made by the World Health Organization, people aged 65 years and over are considered as elderly. Therefore, the patients were divided into two groups as under 65 years and over. The clinicopathological characteristics of the groups were compared.

All analyses were performed using SPSS version 21 (SPSS Inc., Chicago, IL, USA). In descriptive statistical analyses, categorical data were expressed as frequency and percentage. Non-parametric variables were given as median and interquartile range (IQR). The Kolmogorov-Smirnov test was used for assessing the conformity of numerical data to a normal distribution. Chi-square, Fisher's exact and likelilihood ratio tests were used for comparison of categorical variables.

Kaplan-Meier method was used for survival analyses. LogRank test was used for the intergroup survival comparisons. The time from the initiation of treatment until death or the last control date was considered as overall survival (OS). For patients with non-metastatic disease at diagnosis, the time from the initiation of the treatment to first recurrence or death was defined as disease-free survival (DFS). For patients with metastatic stage, the time from the initiation of the treatment to progression or death was defined as progression-free survival (PFS). A multivariate Cox regression model was used to determine the prognostic factors of MBC. A p-value $<0.05$ was considered statistically significant. 


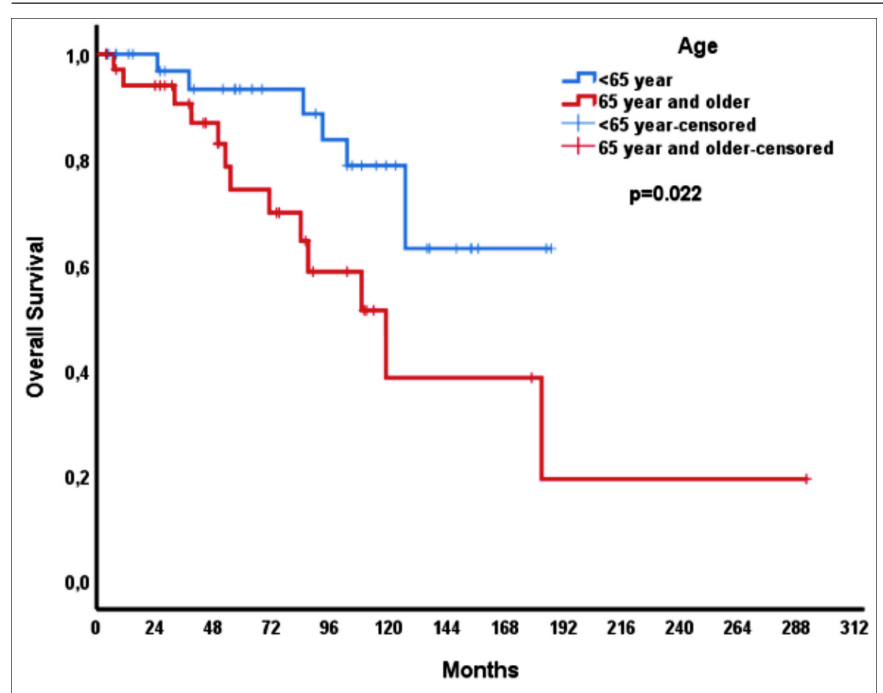

Figure 1: Overall survival according to age.

\section{RESULTS}

Out of 73 patients included in the study, 37 were aged under 65 years, while 36 were aged 65 years or over. Histopathologically, the majority of them had invasive ductal carcinoma (IDC). Of the patients, $65.8 \%$ were in stage $\mathrm{T} 2$, and $60.3 \%$ had lymph node metastasis ( $\mathrm{N} 1=26.0 \%, \mathrm{~N} 2=21.9 \%$, N3 $=$ $12.4 \%$, Table I). ER positivity was $94.5 \%$; while PR positivity was $87.7 \%$, and HER2 positivity was $13.7 \%$. No significant difference was detected between the groups in terms of the clinicopathological characteristics, adjuvant chemotherapy, and adjuvant tamoxifen, when the patients were assessed in two groups, namely, younger (those aged $<65$ ) and elderly (those aged $\geq 65$ ), regarding age (Table I).

The median duration of follow-up was 71 months (Q1-Q3: 31.5-112.5 months); while, 5-year overall survival (OS) for the whole group was $84.3 \%$. It was found that as a result of the univariate analysis, the 5-year OS of the elderly group was lower compared to the younger group ( $74.2 \%$ vs. $93.3 \%, p=0.022$, Figure 1 ). It was determined that those with tumor grade 3 had less 5 -year OS compared to those with tumor grade 1 to $2(74.0 \%$ vs. $100 \%)$. As the tumor T stage advanced, the 5-year survival percentage decreased ( $100 \%, 83.9 \%, 50 \%$, and $33.3 \%$ for $\mathrm{T} 1-4$, respectively, $p=0.022$, Table II). Age, tumor grade, and T stage were included in the multivariate Cox regression analysis and only advanced age was found to be an independent poor prognostic factor (HR: $3.068,95 \% \mathrm{Cl}: 1.013-9.293, \mathrm{p}=0.047$, Table II).

\section{DISCUSSION}

Demographic and clinicopathological characteristics of the patients with non-metastatic MBC were analysed and characteristics, which could have prognostic value, were investigated in this study. It was found that as a result of the study, advanced age (aged $\geq 65$ ) is an independent prognostic factor for patients with non-metastatic MBC.
The 5 -year overall survival was determined to be $79.1 \%$ in a study, which included 10,873 patients with MBC who had been treated between 2004 and $2014 .^{7}$ In a study by Leone et al., in which $52 \%$ of 2,992 patients with MBC were evaluated, 5 -year OS was determined to be $70.6 \%$ in the whole patient group and $60.6 \%$ among the group aged 65 years and over. ${ }^{11}$ In the present study, 5-year survival was found to be $84.3 \%$ in the whole patient group and $74.2 \%$ in the elderly group. The fact that $9 \%$ of the patients in the study of Leone et al. consisted of metastatic patients and that metastatic patients were not included in the study, which could have led to the 5-year OS to be higher in this study. 5year survival was found to be $52 \%$ among elderly patients in the study by Tural et al. ${ }^{12}$ It was determined in the study by Tural et al. that the tumor stage was a prognostic factor, and it was revealed that $12 \%$ of elderly patients had stage T4 tumors. ${ }^{12}$ In the present study, merely $2.8 \%$ of the elderly patients had stage T4 tumors. This might have led to the value of 5-year OS data to be found lower in the study by Tural et al. compared to this study. Leone et al. demonstrated as a result of multivariate analysis that advanced age is an independent poor prognostic factor for people with MBC. ${ }^{11}$ Likewise, advanced age was determined as an independent poor prognostic factor in the present study.

It has been revealed in the previous studies, which have been performed with women who have had breast cancer, that the T stage of the tumor is advanced among patients aged over 70 years, compared to younger people; and it is more prevalent among those with metastatic disease at the time of diagnosis. ${ }^{13,14}$ Whereas, it has been put forward in certain studies that the tumor biology of older female patients with breast cancer might be more favourable compared to younger ones, for instance, HR-positive and HER2-negative tumors. ${ }^{12,15}$ Tural et al. manifested in their study, in which they assessed 99 patients with MBC, that the tumor diameter was larger in those with MBC aged 65 years and over, and that the tumors of elderly patients expressed more ER/PR. ${ }^{12}$ In the present study, no difference was detected between the younger and elderly groups, regarding both tumor size and ER/PR expression. It was reported in the study by Tural et al. that the ER status of 24 $(24.2 \%)$ of 99 patients in total was unknown, and it was stated that the ER status of $30 \%$ of the patients in the younger patient group was not known. ${ }^{12}$ Furthermore, it was revealed in the same study that the rate of ER-positive patients among patients with known ER status in all patient groups was $68.9 \%$; and it was determined to be considerably lower compared to the rates, which have been reported for patients with MBC in the literature. ${ }^{12}$ However, the fact that the ER status of all patients was known in this study and the rate of ER positivity, which have been manifested in the whole patient group, was consistent with the literature, suggests that the reliability of the obtained results was increased. ER positivity was determined to be $94.5 \%$ in the study. Likewise, Leone et al. in their study, have revealed 
that $95.1 \%$ patients had ER-positive tumors. ${ }^{11}$ Moreover, they have demonstrated in the same study that ER status is an independent prognostic factor. ${ }^{11}$ In the present study, the 5-year survival among ER-positive and negative patients was $85.3 \%$ and $66.7 \%$, respectively. However, since the number of patients was lower in this study compared to the study of Leone et al., this numerically obtained difference was not found statistically significant.

HER2 overexpression or amplification is present in $20-25 \%$ of all breast cancers, and HER2 positivity is associated with a poor prognosis. ${ }^{16-18}$ However, a significant prolongation of OS was achieved with the adjuvant use of trastuzumab, a humanised monoclonal antibody that blocks HER2. ${ }^{19,20}$ Her2 overexpression or amplification is less common in men than in women. ${ }^{17}$ In this study, Her2 positivity was found as $13.7 \%$ in the whole group, and this value was compatible with other literature.

The study has several limitations. Since the genetic analysis results of the patients were not known, the impact of genetic factors on survival could not be assessed in the study. Due to the retrospective nature of the study, only breast cancer-related subgroup survival analysis could not be conducted, so non-cancer associated deaths might have impacted the analysis of the overall survival. The fact that the information related to the treatment, which had been received by the patients in the period following they became metastatic, was not available, hindered the investigation of the effects of the treatments on survival.

\section{CONCLUSION}

In patients with operated MBC, whose clinicopathological characteristics were in line with the know literature, advanced age is an independent poor prognostic factor, limitations. It might be crucial to focus particularly on elderly groups, in further clinical trials where new treatments in breast cancer will be investigated.

\section{ETHICAL APPROVAL:}

The study was approved by the local Ethical Committee of the University of Health Sciences, Dr. A.Y. Ankara Oncology Hospital, before the start of study (TUEK Meeting No. 100-18.8.2020).

\section{PATIENTS' CONSENT:}

Informed consents were obtained from all participants or their family, included in the study.

\section{CONFLICT OF INTEREST:}

Author declared no conflict of interest.

\section{AUTHOR'S CONTRIBUTION:}

FCS: Substantial contributions to conception and design, acquisition of data, interpretation of data, drafting of manuscript, reviewing the paper, advices, and final approval.

\section{REFERENCES}

1. Gucalp A, Traina TA, Eisner JR, Parker JS, Selitsky SR, Park $\mathrm{BH}$, et al. Male breast cancer: A disease distinct from female breast cancer. Breast Cancer Res Treat 2019; 173(1):37-48. doi: 10.1007/s10549-018-4921-9.

2. Yoney A, Kucuk A, Unsal M. Male breast cancer: A retrospective analysis. Cancer/Radiothérapie 2009; 13(2): 103-7. doi: 10.1016/j.canrad.2008.11.011.

3. Imamoglu GI, Eren T, Arzu O, Yıldırım N, Karacin C, Baylan $B$. Is tamoxifen use a factor affecting continence in breast cancer patients? Cureus 2019; 11(8):e5417. doi: 10.7759/ cureus.5417

4. Eren T, Karacin C, Ucar G, Ergun Y, Yazici O, İmamoglu G, et al. Correlation between peripheral blood inflammatory indicators and pathologic complete response to neoadjuvant chemotherapy in locally advanced breast cancer patients. Medicine (Baltimore) 2020; 99(22): e20346. doi: 10.1097/MD.0000000000020346.

5. Sarmiento S, McColl M, Musavi L, Gani F, Canner JK, Jacobs $L$, et al. Male breast cancer: A closer look at patient and tumor characteristics and factors that affect survival using the national cancer database. Breast Cancer Res Treat 2020; 180(2):471-9. doi: 10.1007/s10549-020-05556-y.

6. Sites A. SEER cancer statistics review, 1975-2011. Bethesda, MD: National Cancer Institute. 2014.

7. Yadav S, Karam D, Bin Riaz I, Xie H, Durani U, Duma N, et al. Male breast cancer in the United States: Treatment patterns and prognostic factors in the 21 st century. Cancer 2020; 126(1):26-36. doi: 10.1002/cncr.32472.

8. Giordano SH. Breast cancer in men. N Engl J Med 2018; 378:2311-20.

9. Zehr KR. Diagnosis and treatment of breast cancer in men. Radiol Technol 2019; 91: 51m-61m.

10. Masci G, Caruso M, Caruso F, Salvini P, Carnaghi C, Giordano $L$, et al. Clinicopathological and immuno histochemical characteristics in male breast cancer: A retrospective case series. Oncologist 2015; 20(6):586-92. doi: 10.1634/theoncologist.2014-0243.

11. Leone JP, Zwenger AO, Iturbe J, Leone J, Leone BA, Vallejo $\mathrm{CT}$, et al. Prognostic factors in male breast cancer: A population-based study. Breast Cancer Res Treat 2016; 156(3): 539-48.

12. Tural D, Selçukbiricik F, Aydoğan F, Beşe N, Yetmen O, Ilvan Ş, et al. Male breast cancers behave differently in elderly patients. Jpn J Clin Oncol 2013; 43(1):22-7. doi: 10.1093/jjco/hys193.

13. Lodi M, Scheer L, Reix N, Heitz D, Carin AJ, Thiébaut N, et al. Breast cancer in elderly women and altered clinico-pathological characteristics: A systematic review. Breast Cancer Res Treat 2017; 166(3):657-68. doi: 10.1007/s10549-0174448-5.

14. Li B, Hua B, Lu X, Chen Y, Xiao WZ. Treatment options for elderly breast cancer patients over 70 years old. Zhonghua Yi Xue Za Zhi 2013; 93:3523-5.

15. Gennari R, Curigliano G, Rotmensz N, Robertson C, Colleoni $M$, Zurrida $S$, et al. Breast carcinoma in elderly women: Features of disease presentation, choice of local and 
systemic treatments compared with younger postmenopasual patients. Cancer 2004; 101(6):1302-10. doi: 10.1002/cncr. 20535.

16. Chang HR. Trastuzumab-based neoadjuvant therapy in patients with HER2-positive breast cancer. Cancer 2010; 116(12):2856-67. doi: 10.1002/cncr.25120.

17. Ergün Y, Özdemir NY, Yazıcı O, Gökhan U, Açikgöz Y, Öznur $B$, et al. The effect of neoadjuvant trastuzumab treatment sequence on pathologic complete response in HER2-positive locally advanced breast cancer. Bozok Tıp Dergisi 10:47-54.

18. Cronin KA, Harlan LC, Dodd KW, Abrams JS, Ballard-Barbash R. Population-based estimate of the prevalence of HER-2 positive breast cancer tumors for early stage patients in the US. Cancer Invest 2010; 28(9):963-8. doi: 10.3109/ 07357907.2010.496759.

19. Viani GA, Afonso SL, Stefano EJ, De Fendi LI, Soares FV. Adjuvant trastuzumab in the treatment of her-2-positive early breast cancer: A meta-analysis of published randomised trials. BMC Cancer 2007; 7:153. doi: 10.1186/ 1471-2407-7153.

20. Romond EH, Perez EA, Bryant J, Suman VJ, Geyer Jr CE, Davidson NE, et al. Trastuzumab plus adjuvant chemotherapy for operable HER2-positive breast cancer. $N$ Engl J Med 2005; 353(16):1673-84. doi: 10.1056/ NEJMoa052122. 